\title{
E o Twitter criou...Deus! Arquivo, gênero e humor em redes sociais
}

\author{
Janaina Cardoso Brum ${ }^{1}$ \\ Aracy Ernst-Pereira ${ }^{2}$
}

\begin{abstract}
The text deals with the discursive configuration of humoristic statements about gender in the social network Twitter, by considering the play of relationships that characterize the stating (im)possibilities "foreseen" in the file, taken as the law of what can be said, and consequently, of what cannot be said. Such a regularization of the statements that shape the humoristic discursive process many times presents itself as transgression, as discontinuity of the meanings that form a specific region of the file, that is, a discursive formation that, according to Pêcheux, could be a symptom of the understanding of the significant process of the ideological interpellation. Nevertheless, one deals in this article with the humor that authenticates statements that conjure the "sortilege", present in the ideological ritual, of maintenance of a specific social order in which androcentrism prevails.
\end{abstract}

Keywords: Discourse; humor; gender.

Resumo: O texto trata da configuração discursiva de enunciados humorísticos sobre gênero na rede social Twitter, considerando o jogo de relações que caracterizam as (im)possibilidades enunciativas, "previstas" no arquivo, visto como a lei do que pode ser dito e, consequentemente, do que não pode ser dito. Essa regularização dos enunciados que define o processo discursivo humorístico, muitas vezes, apresenta-se como transgressão, como descontinuidade dos sentidos que formam uma determinada região do arquivo, ou seja, uma formação discursiva, o que, em termos pecheuxtianos, poderia ser sintoma da apreensão do processo significante da interpelação ideológica. Todavia, trabalha-se, neste artigo, o humor autenticando enunciados que conjuram o "sortilégio", presente no ritual ideológico, de manutenção de uma determinada ordem social em que prevalece o androcentrismo.

Palavras-chave: Discurso; humor; gênero.

\section{Considerações Iniciais}

Propõe-se, neste artigo, a reflexão de como se estabelece a relação entre o discurso humorístico midiático na rede social Twitter e a construção e manutenção de uma memória produzida pela circulação de um dado arquivo, ligado a saberes do senso comum

1 Doutoranda em Letras na Universidade Católica de Pelotas (UCPel), Integrante do Grupo de Pesquisa do CNPq Prisma e do Laboratório de Estudos em Análise do Discurso (LEAD) Centro de Educação Aberta e a Distância, Pelotas, RS.

2 Professora do PPG-Letras da Universidade Católica de Pelotas (UCPEL), Coordenadora do Grupo de Pesquisa do CNPq Prisma e do Laboratório em Análise do Discurso (LEAD), Pelotas, RS 


\section{Conexão Letras}

que se atualizam a partir da referência ao discurso religioso. Para isso, empreende-se uma reflexão sobre arquivo em sua relação com uma memória que perdura através de materialidades, cujos enunciados repetíveis têm assegurado a permanência do modelo androcêntrico e mimético de simbolização e reprodução do gênero, ainda prevalente na sociedade contemporânea.

O termo "arquivo" origina-se do latim "archívum", lugar em que se guardam documentos, sendo sua acepção mais corrente a que o concebe como conjunto de documentos (papéis oficiais, manuscritos, cartas, fotografias, etc.), referentes a um determinado evento ou período histórico. Nessa acepção, privilegia-se o aspecto físico, material, concreto e técnico, marcado pela positividade e por uma concepção "científica" de história que visa à transcrição sistemática das fontes com vistas à descrição dos fatos ou momentos históricos. Pode assim ser compreendido como um lugar institucional de armazenamento e acesso de dados e fatos, tendo como finalidade a preservação da memória.

Não é nesse sentido que se conduzirá esta reflexão. Diferentemente, com base em Foucault, considera-se a noção de arquivo não como um mero conjunto de documentos chancelados institucionalmente, mas como "sistemas de enunciados 3 ". Opondo-se à visão que o concebe, de forma estática e totalizante, como depositário ou testemunho de todos os textos de uma cultura produzidos no passado, diz o autor:

O arquivo é [...] a lei do que pode ser dito, o sistema que rege o aparecimento dos enunciados como acontecimentos singulares. Mas o arquivo é, também, o que faz com que todas as coisas ditas não se acumulem indefinidamente em uma massa amorfa, não se inscrevam, tampouco, em uma linearidade sem ruptura e não desapareçam ao simples acaso de acidentes externos, mas que se agrupem em figuras distintas, se componham umas com as outras segundo relações múltiplas, se mantenham ou se esfumem segundo regularidades específicas; [...] O arquivo não é o que protege, apesar de sua fuga imediata, o acontecimento do enunciado e conserva, para as memórias futuras, seu estado civil de foragido; é o que, na própria raiz do enunciado-acontecimento e no corpo em que se dá, define, desde o início, o sistema de sua enunciabilidade. $\mathrm{O}$ arquivo não é, tampouco, o que recolhe a poeira dos enunciados que novamente se tornam inertes e permite o milagre eventual de sua ressurreição; é o que define o modo de atualidade do enunciado-coisa; é o sistema de seu funcionamento. (1987, p. 147) [grifo do autor]

Nessa citação, percebe-se um deslocamento conceptual considerável entre a visão tradicional de arquivo e a que é proposta e, portanto, entre o amorfo e o dinâmico, entre o passado inerte e o passado-presente vivo das enunciações, entre uma linearidade sem falhas e uma linearidade sujeita ao equívoco, enfim, entre o registro unificado da diversidade e o funcionamento dos discursos em sua multiplicidade, mas também regularidade. O que opera esse deslocamento é, pois, sua concepção como "sistema geral da formação e da transformação dos enunciados”, em oposição à concepção corrente de depósito memorial de fatos e dados históricos. Dissociada da atualidade dos processos discursivos, a visão tradicional procede a um corte entre o passado (a memória) e o presente dos enunciados. Esse sistema, segundo Foucault, permite o aparecimento das regras de uma prática e

3 Entenda-se "enunciado" na acepção foucaultiana, ou seja, "ele não é em si mesmo uma unidade, mas sim uma função que cruza um domínio de estruturas e de unidades passíveis e que faz com que apareçam, com conteúdos concretos, no tempo e no espaço" (FOUCAULT, 1987, p. 99). Contrapondo-se à formulação que é tomada no tempo curto da atualidade de uma enunciação, o enunciado existe no tempo longo de uma memória. (cf. COURTINE, 2009, p. 106) 
a subsistência e modificação dos enunciados de um arquivo, os quais não são apreensíveis em sua totalidade, porque se organizam por níveis, regiões, fragmentos. Isso permite pensar que, embora não completamente apreensíveis no trabalho de descrição, os enunciados e suas possíveis relações encontram-se em estado virtual, latentes (pressupostos) no nível do interdiscurso, tornando possível sua (re)configuração nas formações discursivas, essas sim passíveis de uma descrição que, embora sem alcançar integralmente o arquivo, atua a partir de seu horizonte. O arquivo relaciona-se assim ao nível de um sistema de formação dos enunciados, que estão aquém da coerência, visibilidade e horizontalidade do que se constrói no plano terminal da formulação (cf. COURTINE, 2009). Esse sistema é também o que determina a possibilidade de agrupamento em rede dos enunciados ou o seu desfazimento. Para a análise das formações discursivas, trata-se, pois, de recuperar os elementos do arquivo em suas relações interdiscursivas, identificando os já-ditos em suas funções enunciativas e no nível de sua existência histórica, sua filiação e relação com o sistema geral de que faz parte e o tipo de relação que mantém com o dito, trabalhando a alteridade e a contradição envolvidas na relação entre os enunciados pretéritos, que dominam a formação discursiva, e a atualidade da enunciação.

No exercício de análise aqui desenvolvido, pretende-se, considerando tais aspectos teóricos, trabalhar a construção dos efeitos de sentido humorísticos a partir da questão básica: "que tipo de relação entre enunciados de um determinado sistema de formação e a linearidade significante é responsável pelo efeito humorístico"? que se desdobra nas seguintes hipóteses: 1) os enunciados que constituem os saberes colocados em jogo na formulação das micro-histórias humorísticas no Twitter atuam aparentemente no âmbito do inconsistente, do imponderável, do non-sens; no entanto, mantêm-se no âmbito dos saberes institucionalizados; 2) a temática do gênero, quando discursivizada no campo do humor, funda-se em representações imaginárias que expõem o caráter desigual da contradição, da irreversibilidade de papéis e da assimetria referentes à dualidade feminino/ masculino construída historicamente.

Para a Análise de Discurso (Pêcheux, 1990; Pêcheux e Gadet, 2010), em sua terceira fase, é possível subverter a ordem ideológica estabelecida. Segundo os autores, são dois os campos discursivos em que a transformação da ordem é mais evidente: o discurso poético e o discurso humorístico. $\mathrm{O}$ entendimento de que o discurso humorístico coloca-se no eixo da polissemia, da multiplicidade e da ruptura com os sentidos estabelecidos é bastante corrente. Todavia, o discurso humorístico, tal como se apresenta hoje, parece, por vezes, reforçar o discurso do senso comum e, como tal, da(s) ideologia(s) dominante(s). Para Ernst-Pereira (1994), a heterogeneidade constitutiva de todo discurso e de toda formação social faz-se sentir também no discurso humorístico, o qual pode voltar-se para o eixo polissêmico tanto quanto para o eixo parafrástico. Considerando, então, seu caráter plural e heterogêneo, pode-se dizer que o discurso humorístico é um lugar de enfrentamento ideológico, mas não necessariamente com enunciados que fundam e mantêm práticas discursivas hegemônicas. Ao contrário, pode confrontar-se com a possibilidade de transformação, de reconfiguração das redes de enunciados, mais ou menos estabilizados, num processo de identificação e continuidade de sentidos que acolhe não o diferente, mas o semelhante.

É isso que se pretende examinar em formulações presentes na rede social Twitter. As redes sociais, nascidas com o advento da Web 2.0, constituem-se num amplo campo para a pesquisa em diversas áreas do conhecimento. $\mathrm{Na}$ área do discurso especificamente, podem ser consideradas campos de confronto ideológico da chamada "pós-modernidade" ou "modernidade tardia". Tratar o discurso humorístico em redes sociais - mais especifi- 
camente no microblog Twitter - possibilita, ao analista de discurso, compreender pontos de emergência, junção ou separação de enunciados num espaço virtual que se caracteriza pela multiplicidade de enunciados e heterogeneidade de posições. A meta deste estudo é identificar, considerando a noção de arquivo, o tipo de relação estabelecida entre os enunciados que provoca o efeito de sentido humorístico. Tomando o microblog Twitter não como "suporte" do discurso, mas como um espaço em que as condições de produção são diferenciadas, analisa-se, neste artigo, a produção de sentidos no discurso humorístico sobre gênero no perfil “Deus (@OCriador)”.

\section{Contemporaneidade e Twitter}

Definir a "contemporaneidade" é tarefa difícil, dada a sua extrema complexidade. Todavia, o que se pretende é caracterizá-la de uma certa maneira, a partir de alguns conceitos referentes ao sujeito, ao momento atual, às tecnologias da informação e da comunicação, de modo a prefigurar um quadro que torne possível situar a reflexão aqui empreendida.

Para Orlandi (2007), pensar o sujeito discursivo implica considerar a articulação entre a língua e a ideologia. Para a autora, a interpelação do indivíduo em sujeito ideológico - e, portanto, histórico - faz-se pelo simbólico. Dessa interpelação, resulta uma forma-sujeito histórica, no caso da contemporaneidade, a forma-sujeito capitalista, com a qual os indivíduos vão se identificar-desidentificar-contra-identificar. A figura da interpelação ideológica implica pensar que o sujeito não é livre e tampouco sua constituição, unívoca. A um só tempo, o sujeito submete-se à ordem da língua e à ordem da ideologia, ambas constituindo a ordem do discurso (cf. Orlandi, 2007).

Dizer que o sujeito contemporâneo é o sujeito capitalista implica uma mudança dada na História: o processo de assujeitamento ideológico produz-se ad infinitum, vinculado, entretanto, às condições sociais existentes. São essas condições que atuam na configuração da forma-sujeito. Nas palavras de Orlandi, "A forma-sujeito, que resulta dessa interpelação pela ideologia é uma forma-sujeito histórica com sua materialidade" (2007, p. 12). Dessa forma, o sujeito da contemporaneidade difere do sujeito da modernidade.

Para o psicanalista Joel Birman (2007), o sujeito atual é incapaz de desejar e de fantasiar. Segundo o autor, estamos expostos a um "excesso intensivo" que leva à precarização dos processos de simbolização, a qual lança o sujeito para a descarga direta desse excesso intensivo. Essa descarga pode ser feita de forma psicossomática (implosão para o corpo) ou através da ação (explosão para o outro). Esta última, para Birman, desdobra-se na violência e na compulsão crescentes na contemporaneidade: "Pode-se afirmar então que o sujeito realiza uma passagem ao ato sobre o corpo, sob a forma de produção de sintomas psicossomáticos, e sobre o mundo, sob a forma da passagem ao ato e as compulsões" (Birman, 2007, p. 30), portanto, sem passar pela fantasia e/ou simbolização.

Esse empobrecimento da fantasia e dos processos de simbolização, aliado à incorporação dos discursos da ciência e da tecnologia, levam a uma experiência psíquica e social degradada, na qual o sujeito impossibilita a experiência intersubjetiva. Assim, chega-se à cultura do narcisismo atual que procede à exclusão do outro, mesmo o outro de si. A alteridade, indesejada e descartável, destitui o sujeito de sua substância (cf. ŽIŽEK, 2010; 2011).

Esse sujeito contemporâneo, segundo Dufour (2005), é, conforme os ensinamentos de Jacques Lacan, reduzido ao estado de produto a ser consumido pelos outros. Para o autor, o duplo sujeito moderno (o sujeito crítico - Kant - e o sujeito neurótico - Freud) está sendo destruído e dando lugar a uma nova forma-sujeito, fruto do desenvolvimento ca- 
pitalista. Essa nova forma-sujeito emerge da mudança substancial da concepção de troca mercadológica; esta se destitui de seus valores transcendentais e morais e passa a valorizar unicamente a mercadoria como tal. Com isso, o valor monetário sobrepõe-se ao valor simbólico, do qual sujeitos e objetos são esvaziados. A isso Dufour chama "dessimbolização do mundo", em consonância com o que diz Birman (2007); "Os homens não devem mais entrar em acordo com os valores simbólicos transcendentes, simplesmente devem se dobrar ao jogo da circulação infinita e expandida da mercadoria" (Dufour, 2005, p. 13).

A forma-sujeito predominante na contemporaneidade é, pois, a de um sujeito aberto aos fluxos incessantes, às contínuas mudanças identitárias e, assim, conveniente à ideologia de mercado. Dufour pergunta-se se o Mercado não constituiria o Grande Sujeito atual. De fato, a ideologia de mercado consiste em pôr diante do sujeito objetos que satisfaçam todo e qualquer desejo: "A narrativa da mercadoria apresenta os objetos como garantia de nossa felicidade e, ademais, de uma felicidade realizada aqui e agora. (Dufour, 2005, p. 76). Essa busca pela satisfação imediata dos desejos pelos objetos é sempre frustrada, de modo que o sujeito busca objetos capazes de satisfazer novos desejos infinitamente. Assim, a ideologia de mercado permanece e se renova, de modo que o ciclo nunca acaba.

Essa fluidez da sociedade de mercado traz, para Haroche (2008), consequências para as personalidades. Como dito anteriormente, a exigência atual é a de que os sujeitos mudem constantemente. Essa exigência de fluidez faz com que um individualismo extremo, o qual caracteriza as sociedades narcísicas (Lasch apud Haroche, 2008), seja predominante. Haroche fala de um "desengajamento" dos sujeitos nas sociedades contemporâneas. Esse desengajamento é resultado das contínuas sensações exercidas sobre os sujeitos, o que modifica a própria constituição subjetiva e as relações intersubjetivas na "hipermodernidade". Imerso na fluidez, o sujeito é destituído da própria capacidade de ter sentimentos, já que estes exigiriam a durabilidade no tempo, ausente nas sociedades líquidas.

Para Haroche, essa personalidade móvel e fluida, que não conhece engajamento e faz de si e dos outros instrumentos, objetos, elege a flexibilidade como maior qualidade social, em detrimento da estabilidade, valorizada na modernidade. Esse estar sempre pronto e aberto para a mudança é característico da personalidade contemporânea. Para Marcel Gauchet (apud Haroche, 2008), "ser eu mesmo" não significa mais saber o que leva o sujeito a agir com liberdade, mas ser capaz de movimentar-se, de aderir ao fluxo contínuo. Nas palavras de Haroche (2008, p. 128): "Dessa forma, a personalidade hipermoderna se caracterizaria pela ausência de engajamento, com a qual o indivíduo está 'ligado, porém distante'. Ele experimenta 'a necessidade da presença dos outros, mas afastado deles', que permanecem abstratos, inconsistentes, permutáveis ou inexistentes."

Em outro texto, Haroche (2009) fala da inexistência de limites entre exterior e interior causada pela ideologia de mercado e pelas tecnologias. Para a autora, o sujeito contemporâneo não encontra limites no virtual e no narcisismo, o que acarreta a perda da capacidade de imaginar o outro. A quantidade de "informações" a que os sujeitos estão expostos nas sociedades de mercado exige uma rapidez, uma competência técnica para assimilá-las que, em contrapartida, não exige atividade mental e capacidade de imaginar (Haroche, 2009).

Com isso, podemos voltar ao que diz Joel Birman (2007). O sujeito contemporâneo, reduzido em sua capacidade de imaginação e simbolização, imerso que está nos fluxos contínuos e na descontinuidade temporal, é impelido a descarregar o excesso intensivo, como já se falou, no próprio corpo ou pela ação. Considerando-se a descarga pela ação e a indiferença e objetificação do outro nas sociedades narcísicas, pode-se dizer que a violência e a agressividade - sejam elas simbólicas ou físicas - são características da contemporaneidade. 
As redes sociais na Internet são particularmente interessantes para se pensar a o sujeito contemporâneo. Segundo Recuero (2011), cada sujeito que se conecta às redes é, ao mesmo tempo, receptor e produtor potencial de informações. O microblog Twitter, no qual é possível compartilhar mensagens curtas (140 caracteres), vem se disseminando tanto como "veículo de informação" quanto como rede social. Nesse espaço, os sujeitos podem exprimir suas opiniões, criar máscaras sociais, forjar personalidades, etc.

As personalidades contemporâneas são, ao mesmo tempo, causa e efeito das redes de informação que se disseminam pela Internet. Mittmann (2008) afirma que o "ciberespaço" modifica a relação dos sujeitos com o conhecimento, as relações intersubjetivas etc., operando-se uma mudança radical nas discursividades. Assim, o computador não é mais apenas "suporte", tampouco a Internet "meio" de interação. A rapidez, o grande fluxo de trocas e a instabilidade gerados pelas novas mídias modificam as ideologias e, em decorrência, as discursividades.

A emergência do ciberespaço como lugar em que os sujeitos podem se expressar e produzir informação poderia levar à concepção errônea de uma liberdade sem fim na contemporaneidade, cuja decorrência seria a morte da ideologia. Segundo Žižek (2011), a era "pós-ideológica" de que alguns teóricos falam é, ao contrário, um novo funcionamento ideológico bastante mais eficiente: sob a aparência da não-ideologia, a ideologia de mercado age e avança satisfatoriamente, de forma naturalizada. A própria tecnologia informática naturaliza-se como uma fonte neutra de informações e produtos, quando na verdade, constitui-se também como infraestrutura controlada por poucas empresas e invisível aos usuários.

Assim, seguindo o modelo da "computação em nuvem", as identidades fragmentadas e descontínuas características da contemporaneidade, bem como o "amplo" acesso a bens culturais e a ilusória liberdade incondicional a que os sujeitos estão continuamente expostos não são neutros e aleatórios, mas produzidos pela própria ideologia de mercado.

\section{Gênero e discurso}

Segundo Funck (1994), gênero pode ser concebido como uma categoria gramatical que tem como forma universal o masculino, enquanto o feminino constitui a variante. Todavia, essa não é sua posição. Para a autora, gênero indica uma construção social, cultural e psicológica, o que vem sendo confundido por muitos com a oposição biológica macho/fêmea (sexo). O gênero (masculino/feminino) é antes uma identidade cultural e social, construída historicamente, muito mais relacionada a aspectos subjetivos do que a aspectos objetivos, como a oposição macho/fêmea.

Sendo assim, as práticas de gênero, como manifestações culturais e sociais, constroem diferentes formas de significação, nas quais diferentes modos de representação são reproduzidos e/ou transformados (cf. SABAT, 2005). Essas representações são da ordem do ideológico. As imagens de gêneros são, muitas vezes, naturalizadas em uma sociedade, sendo que o paradigma masculino é predominante, e isso é refletido nas ordens discursivas. O fato é que o feminino é visto (e representado) geralmente sob a ótica masculina, de forma hegemônica.

Na contemporaneidade, a questão do gênero parece estar resolvida. As mulheres " "tomaram" seu lugar na sociedade e hoje estão em posição de igualdade; todavia, essa afirmação

4 Não se discutirá aqui a definição do termo “mulher”. Todavia, parte-se da consideração de que não existe nada de universal nele; pelo contrário, considera-se que a ilusória universalidade atribuída socialmente ao termo é errônea e parte de generalizações que, em si, engendram sexismo. Para uma discussão maior acerca do tema, ver Butler, Judith. Fundamentos contingentes: o feminismo e a questão do pós-modernismo. $\mathrm{Ca}$ dernos Pagu. Campinas, SP, Unicamp, V. 8, 1998. P. 11-42. 
deve ser relativizada, principalmente em função do imaginário que as cerca. Com efeito, pode-se dizer que ocorreram modificações, pois se a ideologia dominante na atualidade é a ideologia de mercado, isso altera as questões relativas ao gênero, mas concomitantemente permanecem pressuposições fundamentais do paradigma patriarcal dominante.

Historicamente, à mulher sempre foi atribuído um papel passivo e subserviente, sendo considerada propriedade do homem (Butler, 1998); na sociedade contemporânea, ela torna-se produto a ser consumido por ele. Obviamente, opera-se aqui um deslocamento: se antes a mulher era "doada", por seu pai, ao homem com quem se casaria, hoje ela própria se constroi como produto a ser consumido ou descartado, segundo a lógica de mercado, numa armadilha que lhe dá a ilusão de autonomia. Agindo sem perceber as injunções históricas que a determinam, muitas vezes, afirma sua independência em relação ao homem, embora sucumba à força do imaginário que lhe impinge, à revelia, o lugar de dependência psíquica ou financeira.

Essa "independência", reduzindo-se à liberdade de consumo e respondendo às exigências do capitalismo, é um imperativo. A mulher atual, tanto quanto o homem, é livre para escolher: escolhe sua carreira, escolhe seu carro, seu marido, suas roupas e seus sapatos. $\mathrm{O}$ mercado oferece todos os produtos para que goze de sua liberdade. O que explica então que ainda se insista em falar em sexismo? A sociedade contemporânea, ao menos no Ocidente, ainda é patriarcal. Isso significa dizer que os aparelhos ideológicos continuam exercendo sua dominância sob a lógica masculina; e mais: as ideologias cotidianas seguem polarizando o masculino e o feminino, mesmo que de forma sutil - e eficiente -, privilegiando o polo masculino. Isso explica, por exemplo, a grande popularidade de um meme $^{5}$ na rede social Facebook que afirma que as mulheres não tomaram o poder ainda porque não escolheram com que roupa iriam ao evento. Mais surpreendente ainda é o fato de a maior parte das pessoas que compartilham esse meme serem mulheres.

Esse fato implica o que tem sido chamado de violência simbólica: os que estão sob dominação interiorizam o discurso dos dominadores e o reproduzem (cf. Sohiet, 1997). Falar, pois, em violência simbólica significa supor que essa violência se dá pela via do discurso. Entendendo-se aqui o discurso como o lugar em que a base linguística e os processos ideológicos têm sua materialização, pode-se dizer que essa violência é material e produz seus efeitos na ordem social.

\section{E o Twitter criou... Deus!}

O discurso dominante sobre gênero, com base em uma concepção biologicista/cientificista, apresenta universais sobre o que é ser homem ou o que é ser mulher. Esses universais, sob a forma do discurso científico, apresentam-se como verdadeiros. Aparentemente fora do domínio da ideologia, enunciados como "mulheres são sensíveis", "homens são corajosos" não possuem sujeito identificável e, por isso, constituem-se como evidências. Tomando-se ilusoriamente como origem de tais proposições, o sujeito que enuncia faz agir, no interior de seu discurso, o sempre-já-aí do interdiscurso, sob as modalidades do pré-construido e do discurso transverso (Pêcheux, 1988).

Parte-se da ideia exposta anteriormente de que é possível identificar, nos discursos sobre gênero, uma polarização entre feminino e masculino, com a preponderância desse

5 A palavra foi cunhada por Richard Dawkins em 1976, designando originalmente uma unidade mínima de memória destinada a autopropagar-se. Atualmente, está bastante ligada ao funcionamento de redes sociais na Internet e designa principalmente textos verbo-imagéticos curtos que se propagam rapidamente. 


\section{Conexão Letras}

último. Nesse sentido, é lícito perguntar em que medida as micro-histórias, presentes no perfil humorístico “Deus” (@OCriador)no Twitter, lidam com as evidências de sentido decorrentes dessa polarização.

Esse perfil apresenta inúmeras micro-histórias sobre gênero, normalmente tematizando o mito bíblico da criação do mundo a partir das personagens Adão e Eva. Seria possível, então, pensar que as causas do humor, concebido como forma de transgressão, incidiriam ou sobre a questão de gênero ou sobre o "rebaixamento" de uma entidade divina (o Deus da mitologia cristã) para o nível do comum, do trivial. Em qualquer caso, a questão de gênero, relacionada ao humor, engendra práticas discursivas ligadas aos efeitos de pré-construído e de discurso transverso como formas de intervenção do interdiscurso na superfície discursiva.

Nesse sentido, esses dois efeitos apresentam-se, no intradiscurso, como enunciados sem sujeito ou, ainda, como enunciados de um sujeito universal, distinto daquele que se crê controlador de suas palavras e origem de seu pensamento. A pergunta que se impõe, então, é: como caracterizar os efeitos de sentido engendrados pelas discursividades que entram em jogo quando um sujeito-indivíduo assume a posição do que geralmente é identificado como esse sujeito universal pelas ideologias cristãs? O que diz um sujeito (da formulação, cf. Courtine, 2009) quando se diz Deus (sujeito universal, sujeito do enunciado)?

Obviamente, é preciso considerar que o Deus do Twitter é um personagem fictício e insere-se no discurso humorístico, o que potencialmente destituiria esse sujeito universal de sua autoridade em relação aos saberes constituídos em uma determinada região discursivo-ideológica, a saber o âmbito de uma formação discursiva cristã. Veja-se se isso acontece e sob que modalidades:

SDR1: As mulheres sempre foram muito ciumentas: Eva, por exemplo, todos os dias contava as costelas de Adão.

Observa-se que a grande maioria dos microtextos que se referem a gênero no perfil O Criador no microblog Twitter tem estrutura muito simples, proposicional, como na sequência acima. Diante disso, faz-se necessário especificar o entendimento corrente de proposição.

Em lógica, entende-se por proposição - ressalvadas as polêmicas em torno do assunto - frases elementares de que se pode dizer que são verdadeiras ou falsas, contendo, portanto, sempre um julgamento (DUBOIS et al., 2006). Em linguística, a proposição é entendida como o núcleo da frase de base, constituído por um sintagma nominal e um sintagma verbal, em que:

$$
\mathrm{P} \rightarrow \mathrm{SN}+\mathrm{SV}
$$

Entende-se, aqui, proposição como a estrutura linguística composta por um sujeito (sintagma nominal) e um sintagma verbal, que pode constituir-se como via para a materialização dos processos ideológicos. Discursivamente, entende-se a proposição como uma possível formulação, cujas características (deve ser julgada, em lógica, por seu valor de verdade) fornecem-lhe a impressão de veracidade. Para efeitos de análise, a proposição será considerada como a base material cujas características atribuem-lhe impressão de veracidade, linearizando saberes do interdiscurso como se estivessem sempre-já-ali. 
Em outras palavras, a proposição, tal como descrita, constitui-se como base linguística sobre a qual, nesse caso, engendram-se processos discursivo-ideológicos materiais que enunciam verdades sobre o que é ser homem e o que é ser mulher.

A primeira parte da sequência discursiva de referência acima pode ser parafraseada da seguinte maneira: "As mulheres são muito ciumentas", cuja estrutura definitória é de uma proposição afirmativa simples no presente, o que lhe atribui um efeito de sentido de verdade a-histórica. Sintaticamente, ao sujeito "As mulheres", que, por generalização, refere-se à totalidade das mulheres, é atribuída a predicação "muito ciumentas", exemplificada no enunciado que se segue: "Eva, por exemplo, todos os dias contava as costelas de Adão". Tem-se, então, uma proposição afirmativa, cujo valor de verdade é ratificado na sequência pelo exemplo. Essa paráfrase, ao substituir o tempo pretérito pelo presente do indicativo, retira da formulação seu caráter de puro comentário, atribuindo-lhe o estatuto gnômico e, portanto, de atemporalidade e, assim, de valor e sentido universais.

Isso tem a ver com o processo de interpelação ideológica, operada pela identificação com os saberes sempre-já-aí do senso comum que incidem em formações discursivas cristãs e são assumidas pelos sujeitos. Apresenta-se, então, o que Henry (1992) e Pêcheux (1988), na trilha de Louis Althusser, chamaram de desdobramento da forma-sujeito, no qual ${ }^{6}$ o sujeito do enunciado (sujeito universal) recobre o sujeito da enunciação ("locutor"), realizando-se, sob a forma do consentimento, o assujeitamento. Esse recobrimento é, para Pêcheux (1988), o que caracteriza o discurso do bom sujeito. Em contrapartida, não permitir o recobrimento, colocando-se contra a evidência ideológica dos saberes sedimentados, caracteriza o "mau sujeito", aquele que pode, através do humor, expor a apreensão de sua constituição contraditória, isto é, a discrepância existente entre a "estranheza familiar" daquilo que se situa antes e em outro lugar, independentemente, e ele, sujeito identificável, responsável por seus atos. De acordo com Pêcheux, um grande número de brincadeiras, anedotas, etc. são sintomas da apreensão do processo significante na interpelação-identificação (cf. PÊCHEUX, 1988, p. 156). Contudo, "o bom sujeito" pode também, através do humor, continuar a assujeitar-se à ordem instituída, expondo não a rebeldia, mas a adesão ao processo ideológico de determinação e contradição sofrido, num tom lúdico que mascara o fato de a posição hegemônica, nesse espaço, ser muito devastadora em termos de violência simbólica.

Note-se que o humor aparece, na sequência em análise, ligado ao insólito de figuras mitológicas (Deus, Eva, Adão) tratarem de temas cotidianos, triviais, como ciúme e relacionamentos afetivos, e não de objetos religiosos, bíblicos. Esse deslocamento operado na rede de enunciados pretensamente religiosos - Eva, no discurso bíblico, não conta as costelas de Adão (mas ao contá-las ficcionalmente na micro-história reafirma ser o ciúme da mulher histórico) -, introduzidos inesperadamente numa outra rede ligada ao discurso do cotidiano, causa o estranhamento e, nesse caso, o humor. Ligam-se, na linearidade significante, enunciados que pertencem a regiões diferentes do interdiscurso, cuja relação tramada artificialmente gera um efeito de sentido humorístico. A apreensão do processo significante na interpelação-identificação do discurso bíblico, nesse caso, dá-se como efeito aparentemente marginal, até porque se materializa como exemplificação. $\mathrm{Na}$ verdade, o efeito humorístico pretendido na micro-história decorre de um fato bíblico inusitado, cuja formulação constitui-se a partir de um enunciado implícito, pertencente à rede de enunciados cristalizados e evidentes do senso comum: as mulheres são (por

6 “(...) a forma-sujeito 'indivíduo-sujeito', a que apresenta o sujeito como interioridade da individualidade orgânica, é a forma-sujeito constitutiva das ideologias práticas burguesas.” (Henry, 1992, p. 137) 
natureza) ciumentas. Todavia, a aparente subversão do discurso bíblico que caracterizaria a apreensão do processo significante de interpelação-identificação mascara a "estupidez" do "bom sujeito" que permite seu recobrimento pelo sujeito do enunciado, reafirmando a dualidade feminino/masculino.

Sob a forma da articulação (discurso transverso $o^{7}$ ), "As mulheres sempre foram muito ciumentas", apaga-se a relação de exterioridade que o pré-construído estabelece no fio do discurso. Assim, saberes sobre gênero formados além do intradiscurso, sob a dominação ideológica da forma-sujeito, são interiorizados pelo sujeito do enunciado sob a modalidade da evidência (o pré-construído que incide sobre a forma implícita do "todo mundo sabe que as mulheres são ciumentas). Aqui, vê-se a identificação plena do sujeito com a forma-sujeito da FD em questão no que se refere a gênero, embora se possa questionar essa identificação no que se refere ao sagrado, ao divino, conforme colocado anteriormente. Não é à toa que esse sujeito é identificado pelo nome próprio "Deus". Dessa forma, reproduz-se o discurso sem sujeito nem origem do senso comum androcentrista, segundo o qual todas as mulheres são, desde sempre, por referência explícita à gênese da humanidade via texto bíblico (referência a Adão e Eva), ciumentas.

Diante disso, pode-se dizer que o perfil Deus reproduz a ideologia dominante e, ao mesmo tempo em que se coloca, aparentemente, no eixo polissêmico - por fazer piada em nome de "Deus" -, reproduz os padrões estabelecidos pela sociedade capitalista não só relativamente a gênero, mas também a raça, classe etc, como poderiam atestar outras sequências produzidas no âmbito do microblog. Sob um discurso superficialmente transformador, reproduz-se o senso comum, discurso sem sujeito e sem origem, portador de verdades irrefutáveis que recobrem o assujeitamento ideológico.

Veja-se como esse discurso opera em relação ao gênero masculino na SDR a seguir:

SDR2: Como todos os homens bobos, Adão achava suas cantadas óbvias extremamente inteligentes: "Eva, para mim, és a única mulher".

Através da paráfrase "Como todos os homens que são bobos, Adão achava suas cantadas óbvias extremamente inteligentes”, tem-se a forma clássica do pré-construído, uma oração relativa restritiva que, sob a forma do encaixe sintático, atualiza no discurso do sujeito da enunciação, um saber formado em outro lugar. É interessante atentar para o fato de que, se, com relação às mulheres (SDR1), os saberes enunciados diziam respeito à sua totalidade, não é o que acontece em relação aos homens. No caso da SDR2, tem-se acesso a saberes sobre um tipo específico de homens, a saber, aqueles que são bobos. Todavia, nessa construção, ocorre um enunciado - os outros homens são inteligentes, astutos -, advindo de um exterior que não é formulado de forma explícita na proposição.

A existência de dois níveis identificáveis no processo analítico, o do intradiscurso "Existem homens bobos" - e esse saber exterior-anterior, pertencente ao interdiscurso - a saber, "Os homens são astutos" -, traz à superfície uma discrepância entre o que é dito pelo sujeito enunciador e o que é pensado fora, o "impensado do pensamento". Sob a forma do particular ("Alguns homens são bobos"), o saber universalizante sem sujeito nem história é imposto, pela modalidade do pré-construído, como realidade, determinando o sentido do que é dito sem que aquele que enuncia tenha controle sobre o que diz.

Desse modo, se não é intenção do sujeito enunciador atestar um conhecimento universal

7 “... constitui o sujeito em sua relação com o sentido, isto é, representa no interdiscurso aquilo que determina a dominação da forma-sujeito" (Pêcheux, 1988, p. 214-15) 
sobre os homens, é o que acontece através do pré-construído, "na relação dissimétrica por discrepância entre dois 'domínios de pensamento', de modo que um domínio irrompe num elemento de outro (...)" (Pêcheux, 1988, p. 99). Se existem homens bobos (o que poderíamos relacionar com outros pré-construídos, como o de que os homens ficam/tornam-se bobos diante de belas mulheres), eles não representam a totalidade dos homens, pois, pelo senso comum, saber dominante na FD religiosa, os homens são astutos, detentores da "razão", em detrimento das mulheres que, sob o domínio das "emoções", são bobas.

Temos então:

\section{P1: As mulheres são ciumentas.}

P2: Os homens são astutos.

Utilizando-se de estruturas linguísticas muito semelhantes, enuncia-se, em relação à mulher, uma "verdade absoluta", constituída em uma predicação que denota um "defeito" incontestável da totalidade das mulheres, endossada pelos saberes calcados no senso comum segundo os quais a "emoção" é preponderante no feminino; e, em relação ao homem, enuncia uma característica negativa particular que pode ser atribuída apenas a alguns homens, sob a qual se impõe o pré-construído (desde-sempre-já-lá) relativo à "razão" e à astúcia como prerrogativas dos homens. Reproduz-se, assim, o já-dito, cujos saberes interdiscursivos atualizam-se no fio do discurso pelos efeitos de articulação e de encaixe sintático.

Estando o foco do humor, no caso das duas sequências em análise, na intersecção insólita entre divino e comum, pode-se dizer que, quando se trata de gênero, há a reprodução, no fio do discurso, de saberes do senso comum dominantes em relação à dicotomia feminino/masculino. Nesse sentido, o humor, classicamente colocado no eixo polissêmico, volta-se para o eixo parafrástico e reproduz, sob as formas do pré-construído e do discurso transverso, a ordem estabelecida social e discursivamente.

\section{Considerações finais}

Por algum tempo pensou-se que o advento da Web 2.0 constituía-se inquestionavelmente como um acesso irrestrito aos meios pelos quais os sujeitos transformariam as ordens sociais vigentes, visto que discursos minoritários teriam tanto ou maior espaço que os discursos dominantes. Com o tempo, vê-se que essa questão não pode ser colocada de forma tão simples. Vê-se que, ao expressarem-se livremente, os indivíduos assujeitam-se à ideologia, esta que funciona, na contemporaneidade, segundo os moldes da ideologia econômica de mercado (ŽIŽEK, 2011), mais invisível do que o próprio mecanismo de assujeitamento da modernidade.

A eficiência desse funcionamento ideológico invisível deve-se, segundo Žižek (2011), ao fato de que se apresenta sob a forma da não-ideologia. Em um mundo pretensamente "pós-ideológico", todos são donos de si e de suas palavras, perpetuando-se a ilusão de que o sujeito é fonte e controla o que diz (PÊCHEUX, 1988), de que todos podem produzir discursos que subvertem a ordem - uma ordem antiga, superada pela ampla liberdade (de comércio, de consumo) da contemporaneidade.

É assim que um espaço como o Twitter, no qual o controle exercido é totalmente invisível aos olhos dos "sujeitos-consumidores" (cf. ŽIŽEK, 2011), constitui-se como espaço de repetição das relações de produção (dos sentidos). Ele dá lugar a um discurso humorístico que articula o discurso do senso comum ao religioso, perpetuando estereótipos como os assinalados neste estudo. 


\section{Conexão Letras}

Compreender, pois, nesse espaço, a forma (in)verossímel que tomam as relações entre enunciados de diferentes sistemas de formação, relativos ao discurso do senso comum e ao discurso religioso -, materializados na linearidade significante de maneira estranha e inusitada, implica considerar a flexibilidade do arquivo. A partir dele, foi possível produzir a descrição e a interpretação das micro-histórias, num exercício de análise que, recuperando os elementos e as relações interdiscursivas, buscou especificar a natureza singular dessas relações na constituição do humor.

\section{Referências}

BIRMAN, Joel. O sujeito desejante na contemporaneidade. In: FERREIRA, Maria Cristina e INDURSKY, Freda. Análise do discurso no Brasil: mapeando conceitos, confrontando limites. São Carlos: Claraluz, 2007.

BUTLER, Judith. Fundamentos contingentes: o feminismo e a questão do pós-modernismo. Cadernos Pagu. Campinas, SP, Unicamp, v. 8, 1998. p. 11-42.

COURTINE, Jean-Jacques.Análise do discurso político: o discurso comunista endereçado aos cristãos. São Carlos: EdUFSCar, 2009.

DUBOIS, Jean et all. Dicionário de Linguística. Trad. Isidoro Blikstein. São Paulo:

Cultrix, 2006.

DUFOUR, Dany-Robert. A arte de reduzir as cabeças: sobre a nova servidão na sociedade ultraliberal. Trad. Sandra Regina Felgueiras. Rio de janeiro: Companhia de Freud, 2005. ERNST-PEREIRA, Aracy. Na inconsistência do humor, o contraditório da vida: o discurso proverbial e o discurso de alterações, 1994. 165 f. Tese (Doutorado em Letras) Pontifícia Universidade Católica do Ri Grande do Sul, Porto Alegre, 1994.

FERREIRA, Maria Cristina e INDURSKY, Freda. Análise do discurso no Brasil: mapeando conceitos, confrontando limites. São Carlos: Claraluz, 2007.

FOUCAULT, Michel. A arqueologia do saber. Rio de Janeiro: Forense-Universitária, 1987.

FUNCK, Susana B.. Da Questão da Mulher à Questão do Gênero. IN: FUNCK, Susana

B. (org.). Trocando Idéias sobre a Mulher e a Literatura. Florianópolis, SC: Pós-Graduação em Inglês - UFSC, 1994.

FURNALETTO, Maria M.. Para uma Abordagem do Gênero: Animus, Anima. IN:

FUNCK, Susana B. (org.). Trocando Idéias sobre a Mulher e a Literatura. Florianópolis, SC: Pós-Graduação em Inglês - UFSC, 1994.

HAROCHE, Claudine. O outro e o eu na fluidez e desmedida das sociedades contemporâneas. Uberlândia: Edufu, 2009.

HENRY, Paul. A ferramenta imperfeita. Língua, sujeito e discurso. Trad. Maria Fausta P. de Castro. Campinas: Editora da UNICAMP, 1992.

MITTMANN, Solange. Redes e ressignificações no ciberespaço. In: ROMÃO, L.M.S.; GASPAR, N.R.(Orgs.) Discurso midiático: sentidos de memória e arquivo. São Carlos: Pedro \& João, 2008.

NAXARA, M. R. C.; MARSON, I. A.; MAGALHÃES, M. B. de. (Org.). Figurações do outro na história. Uberlândia: Edufu, 2009.

ORLANDI, Eni. O sujeito discursivo contemporâneo: um exemplo. In: FERREIRA, Maria Cristina e INDURSKY, Freda. Análise do discurso no Brasil: mapeando conceitos, confrontando limites. São Carlos: Claraluz, 2007. 
PÊCHEUX, Michel. O discurso: estrutura ou acontecimento.Trad. Eni P. Orlandi. Campinas: Pontes, 1990. . Semântica e discurso: uma crítica à afirmação do óbvio. Trad.Eni P. Orlandi et al. Campinas: UNICAMP, 1988. . e GADET, Françoise. A língua inatingivel: o discurso na história da lingüística. Trad. Bethânia Mariani e Maria Elizabeth Chaves de Mello. Campinas: Editora RG, 2010. RECUERO, Raquel. Deu no Twitter, alguém confirma? Funções do Jornalismo na Era das Redes Sociais. Disponível em www.raquelrecuero.com. Consulta em 23 de novembro de 2011.

. e ZAGO, Gabriela. A Economia do Retweet: Redes, Difusão de Informações e Capital Social no Twitter. Disponível em www.raquelrecuero.com. Consulta em 23 de novembro de 2011.

SABAT, Ruth. Imagens de gênero e produção da cultura. IN: FUNCK, Susana; WIDHOLZER, Nara. (Org.). Gênero em discursos da mídia. 1 ed. Florianópolis/ Sta Cruz do Sul: Mulheres / Edunisc, 2005.

SEIXAS, Jacy Alves de. A imaginação do olhar do outro e as subjetividades narcísicas: um olhar sobre a in-visibilidade contemporânea (o mal-estar de Flaubert no Orkut). In: NAXARA, M. R. C.; MARSON, I. A.; MAGALHÃES, M. B. de. (Org.). Figurações do outro na história. Uberlândia: Edufu, 2009. P. 63-88

SOIHET, Rachel. Violência Simbólica: saberes masculinos e representações femininas. Revista Estudos Feministas, Florianópolis, v.5, n.1, p-7-30,1997.

ŽIŽEK, Slavoj. Como ler Lacan. Trad. Maria Luiza Borges. Rio de Janeiro: Zahar, 2010. . Primeiro como tragédia, depois como farsa. Trad. Maria Beatriz de Medina. São Paulo: Boitempo, 2011. 